\title{
Detailed Simulink implementation for induction motor control based on space vector pulse width modulation SVPWM
}

Taha A. Hussein, Laith A. Mohammed

Department of Electrical Power Techniques Engineering, Engineering Technical College, Northern Technical University, Mosul, Iraq

\begin{tabular}{|c|c|}
\hline Article Info & ABSTRACT \\
\hline Article history: & Space vector pulse width modulation (SVPWM) generates less harmonic \\
\hline Received Oct 13, 2020 & distortion in the output voltage or currents, provides more efficient use of \\
\hline Revised May 8, 2021 & modulation (PWM). In this work, a detailed Simulink implementation for \\
\hline Accepted May 19, 2021 & $\begin{array}{l}\text { SVPWM for the open loop control of permanent magnet synchronous motor } \\
\text { (PMSM) is presented. Results show the output of the blocks that assembles }\end{array}$ \\
\hline Keywords: & $\begin{array}{l}\text { SVPWM besides the PMSM voltages and currents when exposing the motor } \\
\text { to different load torques. The technique of SVPWM enables the load to }\end{array}$ \\
\hline $\begin{array}{l}\text { Induction motor } \\
\text { Inverter } \\
\text { PMSM }\end{array}$ & $\begin{array}{l}\text { respond to the change in external load torque. This technique also results in } \\
\text { lower total harmonic distortion and better utilization of the direct current } \\
\text { (DC) supply compared with traditional sinusoidal pulse width modulation } \\
\text { sinusoidal pulse width modulation (SPWM). }\end{array}$ \\
\hline SPWM & \\
\hline
\end{tabular}

This is an open access article under the CC BY-SA license.

\section{Corresponding Author:}

Taha Ahmed Hussein

Department of Electrical Power Techniques Engineering

Technical College Engineering College

Northern Technical University, Mosul, Iraq

Email: taha_hussian@yahoo.com

\section{INTRODUCTION}

Harmonic reduction in inverters and other electrical systems is important which results in higher operating efficiency. Increasing the switching frequency reduces harmonics in the output in pulse width modulation (PWM) inverters. Induction motors are mostly controlled using PWM inverters. Sinusoidal pulse width modulation (SPWM) is considered as efficient technique but limited to 0.78 modulation index. To work with modulation index up to 0.9 space vector pulse width modulation space vector pulse width modulation (SVPWM) is appropriate solution besides it reduces the total harmonic distortion (THD) and increases the fundamental component of the output inverter voltage [1]-[3]. Induction motors have poor dynamic response in correlation to the direct current (DC) motor. The SVPWM technique is widely used because of their better DC utilization and practical digital realization [4]-[7]. Comparing the performance of SPWM and SVPWM based inverter has been analyzed in MATLAB/Simulink from the analysis of speed regulation, torque ripple and total harmonic distortion [8]-[10]. In alternating current (AC) systems we are sensing AC signals to be used as control variables for finding the performance of the systems. If these ac control signals are replaced by DC quantities (called AC to DC frame transformation) a much better performance can be achieved because dc signals is simpler and having a better bandwidth. This transformation principle is based on converting ac signals to DC and then operate on these DC values and then back transform it to AC domain where they became AC signals. 


\section{DETERMINATION OF SVPWM SIMULINK BLOCK}

\subsection{Calculate $V_{\text {ref }}$ and its position 0}

Figure 1 shows a three phase resultant vector $V_{r e f}$ at certain instant of time. The reference vector is the control variable in space vector technique and is shifted by an angle $\alpha$ from the $\alpha$ axis. This will transform three phase system to two phase system. This vector is first decomposed into two phase ac components resulting in $V_{\alpha}$ and $V_{\beta}$. This is known as three phases to $\alpha-\beta$ transformation and will simplify the analysis. In order to transform these two-phase ac control variables into dc components another two axis are inserted and known as direct and quadrature axis $(d-q$ axis $)$ which is shifted by a time varying angle $(\rho=w t)$ and have the same frequency as $V_{\text {ref }}$ [11], [12]. This makes the $d-q$ axis to be synchronized with three phase supply frequency. Now if $V_{r e f}$ is projected on d-q axis at any instant of time then we obtain two constant values control variables (DC values), namely $V_{d}$ and $V_{q}$.

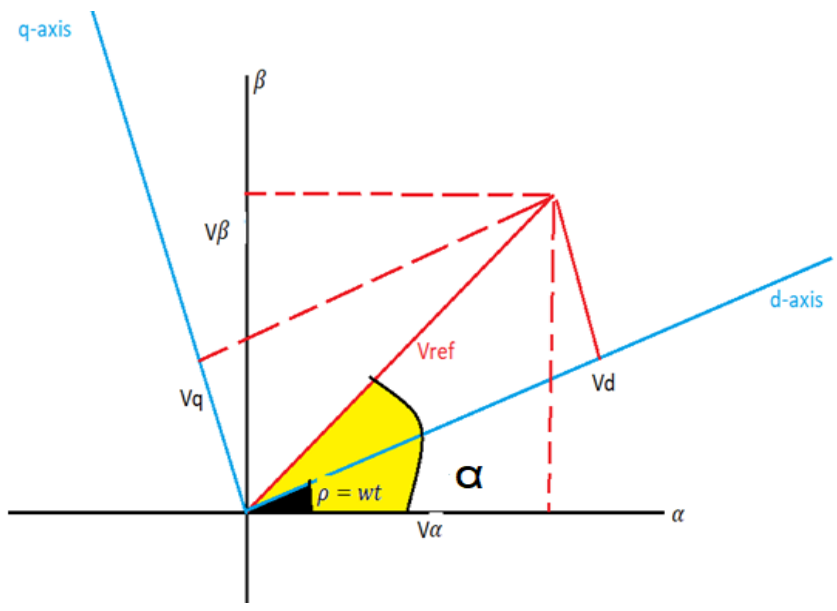

Figure 1. d-q presentation

We could relate the components $V_{d}$ and $V_{q}$ in terms of the three phase input signals $V_{a}, V_{b}$ and $V_{c}$ in terms of the transformation matrix:

$$
\left[\begin{array}{l}
V_{d} \\
V_{q}
\end{array}\right]=\frac{2}{3}\left[\begin{array}{ccc}
1 & -\frac{1}{2} & -\frac{1}{2} \\
0 & \sqrt{3 / 2} & -\sqrt{3 / 2}
\end{array}\right]\left[\begin{array}{l}
V_{a} \\
V_{b} \\
V_{c}
\end{array}\right]
$$

The reference vector $V_{r e f}$ and its position inside the hexagon $(\alpha)$ in Figure 1 can be found as (2).

$$
V_{\text {ref }}=\sqrt{V_{d}^{2}+V_{q}^{2}} \text { where } \alpha_{\rho}=\tan ^{-1} \frac{V_{q}}{V_{d}}
$$

The reference vector will rotate with frequency equal to the system frequency $(\mathrm{f}=50 \mathrm{~Hz}$ ) with radian frequency $w=2 \pi f$ and its projection on the $d-q$ axis is constant. The Simulink box for step1 uses $\mathrm{f}=50 \mathrm{~Hz}$ and the input signal rms value $=230 \mathrm{Volt}$ ). The angle $\alpha$ which is varied from $-\pi$ to $\pi$ for one complete cycle. In order to avoid negative values a constant value of $\pi$ is added in the Simulink model so the variation in $\alpha$ is considered between 0 to $2 \pi$. Figure 2 shows the implementation of $V_{\text {ref }}$ and its position $\alpha$

\subsection{Calculation of the modulation index and identifying the hexagon sector}

The modulation index controls the average output voltage of the three-phase inverter. It is the relation between the reference vector and the dc supply voltage Vdc of the inverter. The modulation index (m) for SVPWM can be found from $=$ Vref $/\left(\frac{2}{3}\right) V d c$. The Hexagon has six sectors each of them house $\pi / 3$ radians. For example, sector 1 is the area between vectors $V_{1}$ and $V_{2}$ (i.e. $0 \leq$ angle $\leq 1.0472 \mathrm{rad}$ ). Figure 3 (see Appendix) shows the Simulink implementation of step2. 


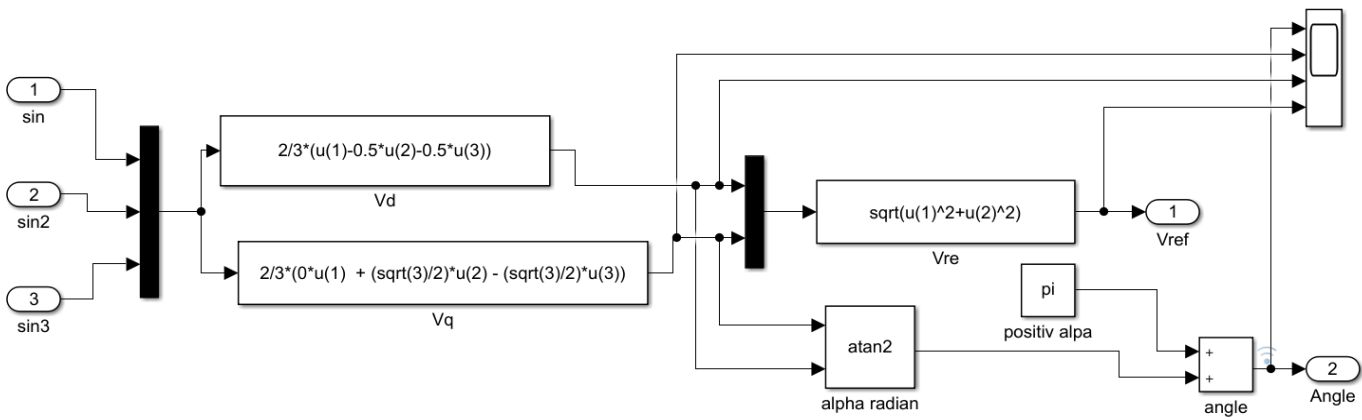

(a)

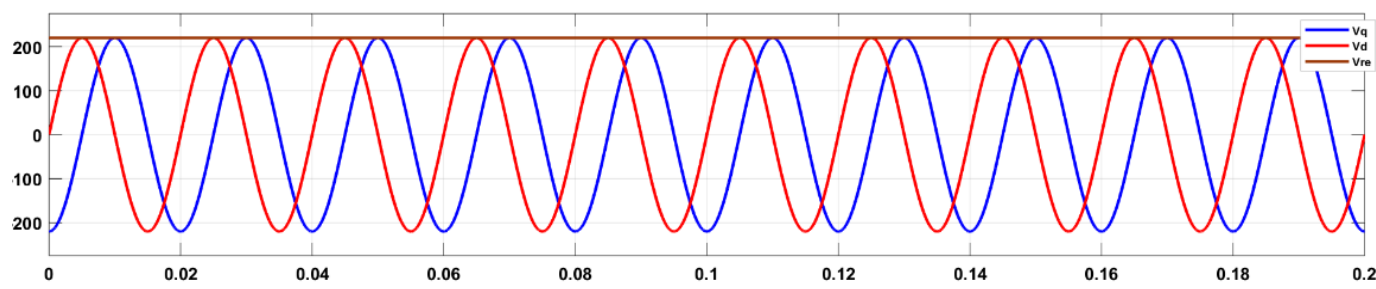

(b)

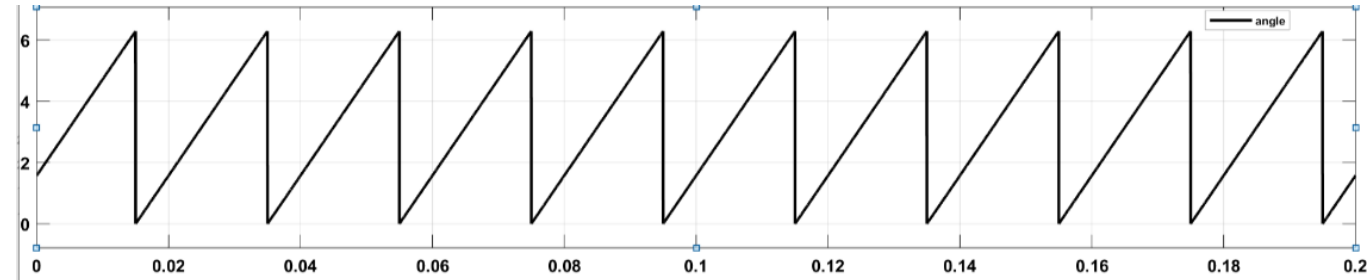

(c)

Figure 2. Calculation of $V_{\text {ref }}$ and its position $\alpha$; (a) sim. block (b) $V_{r e f}, V_{d}, V_{q}$, and (c) angle $\alpha$ for $V_{r e f}$

\subsection{Operating times for insulated gate bipolar junction transistors (IGBJT's) switches}

To get the desired output voltage and frequency the status of each IGBJT transistor switch must be changed between on and off conditions. In three phase inverter topology there are six switches, three of them are connected to the upper leg while the other three are connected to the lower leg as shown previously in Figure 4. In order to reduce switching losses at the output the pattern of switching states is controlled in such a way that the upper leg switches are allowed to transit to the next operating state with only one change in states of the switches. The statues of the three switches on the lower leg are complementary to the switches at the upper leg. There are eight possible combination states for the three upper leg switches, six of them are called the active state i.e. 100,110,010,001,011 and 101 where 1 is considered as ON while 0 is considered as OFF and the remaining two states are 000 and 111 which are added to enable the switches to transit their states as mentioned before. These two states are called passive states because the output voltage is zero. Therefore, the corresponding passive state vectors are called the zero vectors and are located at the origin of the hexagon as shown in Figure 4 (b). The eight states are tabulated in Table 1 with their phase voltage and the corresponding space vector values for the case of three-phase inverter with $180^{\circ}$ conduction [13]-[16].

The area enclosed between two adjacent vectors form one sector. For example, sector 1 is the area between Vectors $V_{1}$ and $V_{2}$. The time taken by sector 1 and sector 2 for example are collected in Table 2 and shown in Figure 5. The procedure is repeated for the other remaining sectors. It is allowed to turn only one of the switches ON or OFF on the upper leg to reduce switching losses. The period of the operating frequency is defined as $\mathrm{T}_{\mathrm{Z}}$ and if we consider sector 1 the on time for Vectors $V_{1}$ and $V_{2}$ and the null vector $\left(V_{o}\right.$ or $\left.V_{7}\right)$ are $T_{1}, T_{2}$ and $T_{o / 2}$ respectively. The on time for the upeer leg switches calculated from null state $(000)$ toward the centre of Figure 4 which is called right aligned is the same as the time calculated from the null state (111) from the centre of Figure 4 to the end of the Figure 4 which is called left aligned. The on time for $S_{1}$ is $T_{1}+$ $T_{2}+T_{o / 2}$ while in sector 2 is $T_{2}+T_{o / 2}$. Following the above constrains on the six switches the time pattern is shown in Table 3 . 


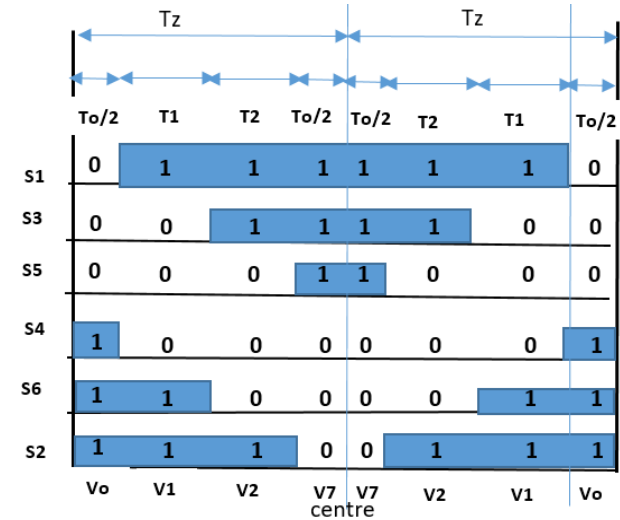

(a)

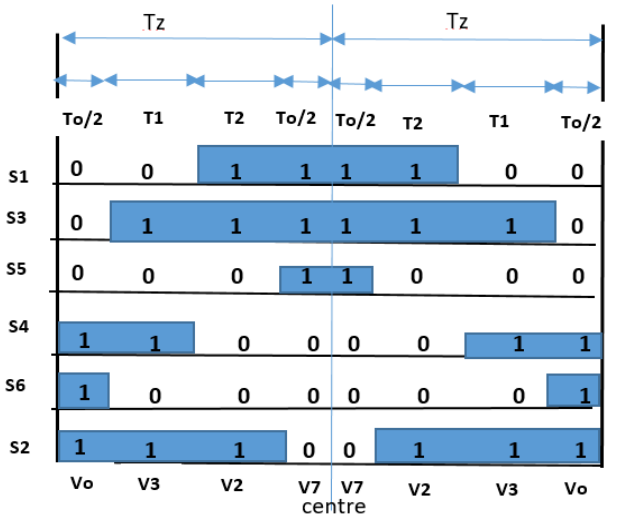

(b)

Figure 4. Switches states ( $S_{1}$ to $S_{6}$ vs $T_{1}, T_{2}$ and $T_{o}$ ); (a) for sector 1 and (b) for sector 2

Table 1. Eight hexagon states with phase voltages and space vectors

\begin{tabular}{cccccccc}
\multicolumn{4}{c}{ Variable } & \multicolumn{3}{c}{ Phase voltages } & \multicolumn{2}{c}{ Space vector } \\
\hline $\mathrm{A}$ & $\mathrm{b}$ & $\mathrm{C}$ & Van & Vbn & Vcn & $\vec{S}=V_{d}+j V_{q}$ & $\vec{S}$ \\
1 & 0 & 0 & $2 / 3$ & $-1 / 3$ & $-1 / 3$ & $2 / 3+j 0$ & $2 / 3 \angle 0^{\circ}$ \\
1 & 1 & 0 & $1 / 3$ & $1 / 3$ & $-2 / 3$ & $1 / 3+j(1 / \sqrt{3})$ & $2 / 3 \angle 0^{\circ}$ \\
0 & 1 & 0 & $-1 / 3$ & $2 / 3$ & $-1 / 3$ & $-1 / 3+j(1 / \sqrt{3})$ & $2 / 3 \angle 0^{\circ}$ \\
0 & 1 & 1 & $-2 / 3$ & $1 / 3$ & $1 / 3$ & $2 / 3+j 0$ & $2 / 3 \angle 0^{\circ}$ \\
0 & 0 & 1 & $-1 / 3$ & $-1 / 3$ & $2 / 3$ & $-1 / 3-j(1 / \sqrt{3})$ & $2 / 3 \angle 0^{\circ}$ \\
1 & 0 & 1 & $1 / 3$ & $-2 / 3$ & $1 / 3$ & $1 / 3-j(1 / \sqrt{3})$ & $2 / 3 \angle 0^{\circ}$ \\
0 & 0 & 0 & 0 & 0 & 0 & $0+j 0$ & 0 \\
1 & 1 & 1 & 0 & 0 & 0 & $0+j 0$ & 0 \\
\hline
\end{tabular}

Table 2. Time taken by vectors $V_{0}$ to $V_{7}$ in sectors 1 and sector 2

\begin{tabular}{cllcll}
\hline \multicolumn{3}{c}{ Sector 1 } & \multicolumn{3}{c}{ Sector 2} \\
\hline Vector & State & Time & Vector & State & Time \\
$V_{0}$ & 000 & To/2 & $V_{0}$ & 000 & To/2 \\
$V_{1}$ & 100 & $\mathrm{~T} 1$ & $V_{3}$ & 010 & $\mathrm{~T} 2$ \\
$V_{2}$ & 110 & $\mathrm{~T} 2$ & $V_{2}$ & 110 & $\mathrm{~T} 1$ \\
$V_{7}$ & 111 & $\mathrm{To} / 2$ & $V_{7}$ & 111 & $\mathrm{To} / 2$ \\
\hline
\end{tabular}

Table 3. The complete table for the all-timing switches in the six sectors

\begin{tabular}{llllll}
\hline \multicolumn{1}{c}{ Sector 1} & \multicolumn{1}{c}{$\mathrm{Sector} 2$} & \multicolumn{1}{c}{ Sector 3} & \multicolumn{1}{c}{$\mathrm{Sector} 4$} & \multicolumn{1}{c}{$\mathrm{Sector} 5$} & \multicolumn{1}{c}{$\mathrm{Sector} 6$} \\
\hline $\mathrm{S} 1=T_{1}+T_{2}+T_{o / 2}$ & $\mathrm{~S} 1=T_{1}+T_{o / 2}$ & $\mathrm{~S} 1=T_{o / 2}$ & $\mathrm{~S} 1=T_{o / 2}$ & $\mathrm{~S} 1=T_{2}+T_{o / 2}$ & $\mathrm{~S} 1=T_{1}+T_{2}+T_{o / 2}$ \\
$\mathrm{~S} 3=T_{2}+T_{o / 2}$ & $\mathrm{~S} 3=T_{1}+T_{2}+T_{o / 2}$ & $\mathrm{~S} 3=T_{1}+T_{2}+T_{o / 2}$ & $\mathrm{~S} 3=T_{1}+T_{o / 2}$ & $\mathrm{~S} 3=T_{o / 2}$ & $\mathrm{~S} 3=T_{o / 2}$ \\
$\mathrm{~S} 5=T_{o / 2}$ & $\mathrm{~S} 5=T_{o / 2}$ & $\mathrm{~S} 5=T_{2}+T_{o / 2}$ & $\mathrm{~S} 5=T_{1}+T_{2}+T_{o / 2}$ & $\mathrm{~S} 5=T_{1}+T_{2}+T_{o / 2}$ & $\mathrm{~S} 5=T_{1}+T_{o / 2}$ \\
$\mathrm{~S} 4=T_{o / 2}$ & $\mathrm{~S} 4=T_{2}+T_{o / 2}$ & $\mathrm{~S} 4=T_{1}+T_{2}+T_{o / 2}$ & $\mathrm{~S} 4=T_{1}+T_{2}+T_{o / 2}$ & $\mathrm{~S} 4=T_{1}+T_{o / 2}$ & $\mathrm{~S} 4=T_{o / 2}$ \\
$\mathrm{~S} 6=T_{1}+T_{o / 2}$ & $\mathrm{~S} 6=T_{o / 2}$ & $\mathrm{~S} 6=T_{o / 2}$ & $\mathrm{~S} 6=T_{2}+T_{o / 2}$ & $\mathrm{~S} 6=T_{1}+T_{2}+T_{o / 2}$ & $\mathrm{~S} 6=T_{1}+T_{2}+T_{o / 2}$ \\
$\mathrm{~S} 2=T_{1}+T_{2}+T_{o / 2}$ & $\mathrm{~S} 2=T_{1}+T_{2}+T_{o / 2}$ & $\mathrm{~S} 2=T_{1}+T_{o / 2}$ & $\mathrm{~S} 2=T_{o / 2}$ & $\mathrm{~S} 2=T_{o / 2}$ & $\mathrm{~S} 2=T_{2}+T_{o / 2}$ \\
\hline
\end{tabular}

To calculate $T_{1}, T_{2}$ and $T_{o / 2}$ we refer to Figure 4 . In sector 1 the area enclosed by vectors $V_{1}$ and $V_{2}$ can be found as:

$$
\begin{aligned}
& \int_{0}^{T_{z}} V_{r e f} d t=\int_{0}^{T_{1}} V_{1} d t+\int_{T_{1}}^{T_{1}+T_{2}} V_{2} d t+\int_{T_{1}+T_{2}}^{T_{Z}} V_{o} d t \\
& V_{r e f} T_{z}=V_{1} T_{1}+V_{2} T_{2}+V_{o}\left(T_{z}-T_{1}-T_{2}\right)
\end{aligned}
$$

The q-axis component is: 


$$
\begin{aligned}
& V_{\text {ref }} T_{z} \sin \alpha=\frac{2}{3} V_{s} T_{1} \sin (0)+\frac{2}{3} V_{s} T_{2} \sin \left(\frac{\pi}{3}\right) \\
& T_{2}=a \frac{\sin \alpha}{\sin \frac{\pi}{3}} T_{Z} \\
& \text { Where } a=\frac{V_{r e f}}{\frac{2}{3} V_{s}} \text { is the modulation index }
\end{aligned}
$$

The d-axis component is:

$$
\begin{aligned}
& V_{\text {ref }} T_{z} \cos \alpha=\frac{2}{3} V_{s} T_{1} \cos (0)+\frac{2}{3} V_{s} T_{2} \cos \left(\frac{\pi}{3}\right) \\
& T_{1}=a \frac{\sin \left(\frac{\pi}{3}-\alpha\right)}{\sin \left(\frac{\pi}{3}\right)} T_{z} \\
& T_{o}=T_{z}-T_{1}-T_{2}
\end{aligned}
$$

The general form of $T_{1}$ and $T_{2}$ for all the six sectors can be written as

$$
\begin{aligned}
& T_{1}=a \frac{\sin \left(\frac{k \pi}{3}-\alpha\right)}{\sin \left(\frac{\pi}{3}\right)} T_{z} \\
& T_{2}=a \frac{\sin \left(\alpha-\frac{(k-1) \pi}{3}\right)}{\sin \frac{\pi}{3}} T_{z}
\end{aligned}
$$

where $\mathrm{k}$ is the sector number. Figure 5 (a) shows the Simulink model for calculating $T_{1}, T_{2}$ and $T_{3}$. The output of the model (i.e. $T_{1}, T_{2}$ and $T_{0}$ ) is shown in Figure $5(\mathrm{~b})$.

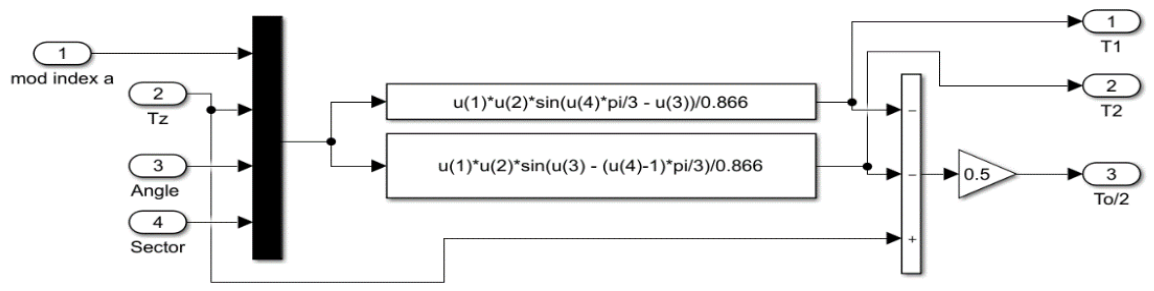

(a)

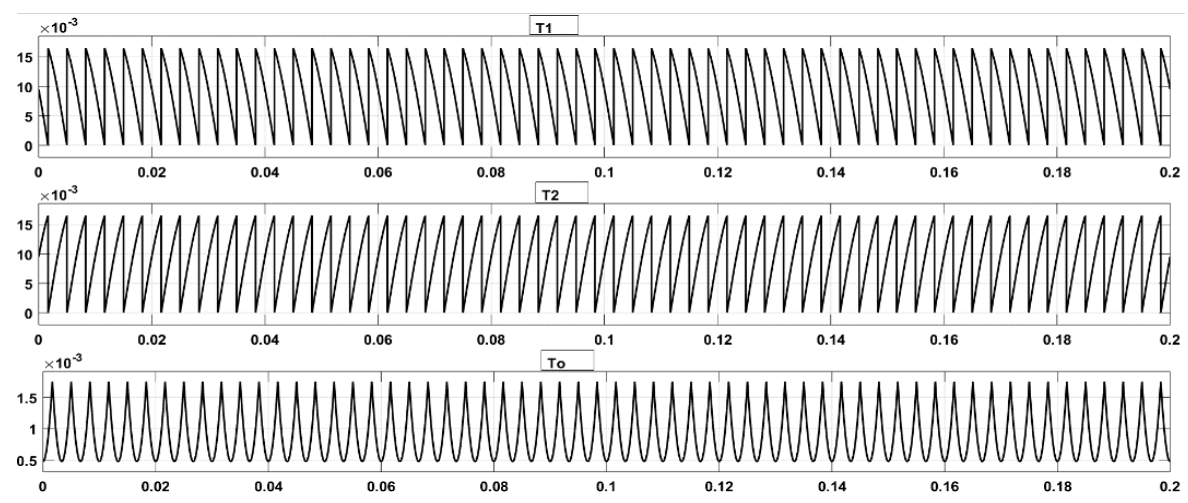

(b)

Figure 5. Operating times for IGBJT's switches; (a) simulink block and (b) $T_{1}, T_{2}$ and $T_{0}$

\subsection{Determination of the control signals}

The time segments for switches S1, S2 and S3 are handed to a multi-port switch as shown in Figure 6 (a) for identifying the sector in the corresponding time instant. The output is the three controlled signals as shown in Figure 6 (b). These signals are then compared with the triangular carrier signal to form the space vector pulse width modulated pulses as shown in Figure 6 (c). These pulses are the triggering signals to the IGBJTs in the three-phase inverter. The Simulink blocks obtaining SVPWM three phase inverter is shown in Figure $6(\mathrm{~d})$.

Detailed Simulink implementation for induction motor control based on space vector ... (Taha A. Hussein) 


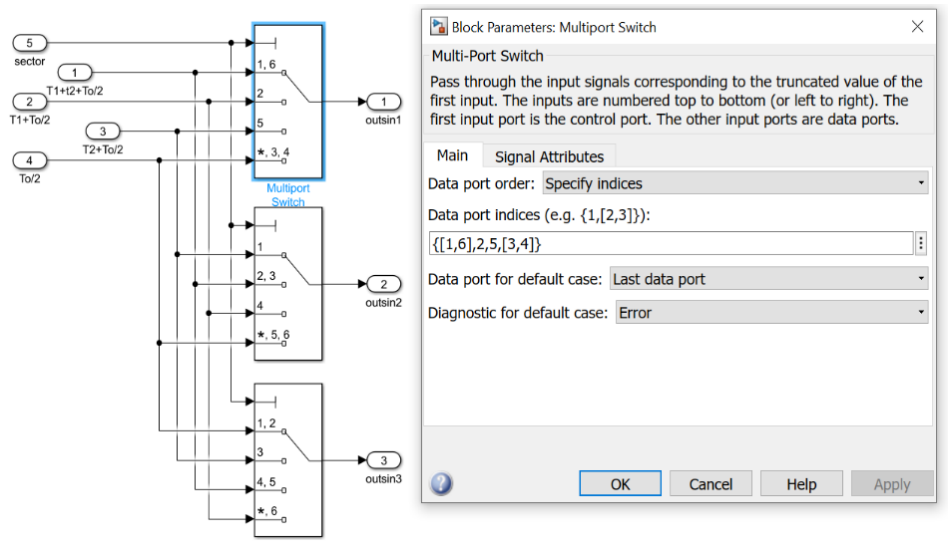

(a)

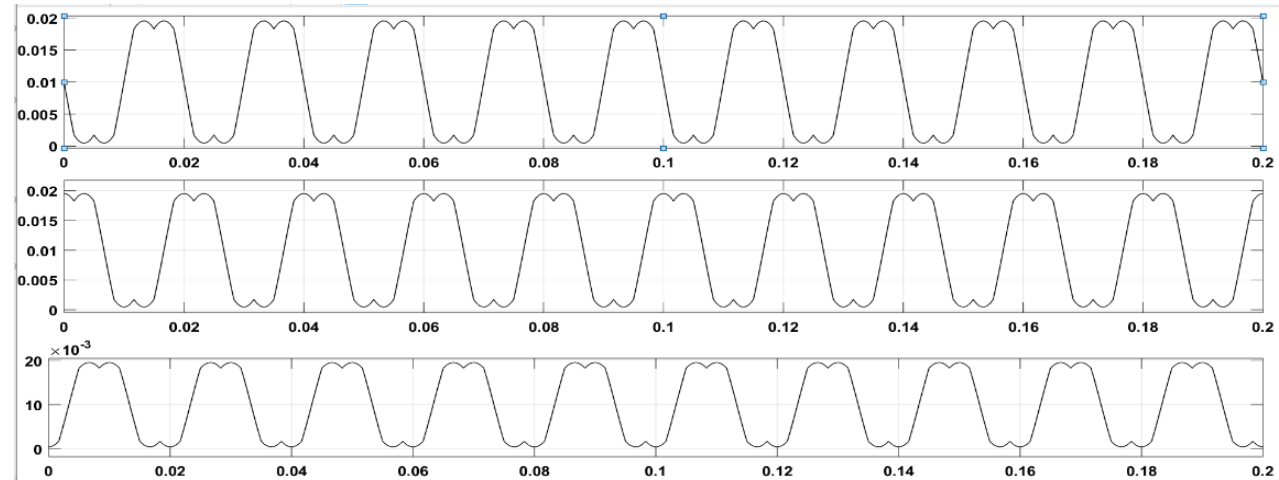

(b)
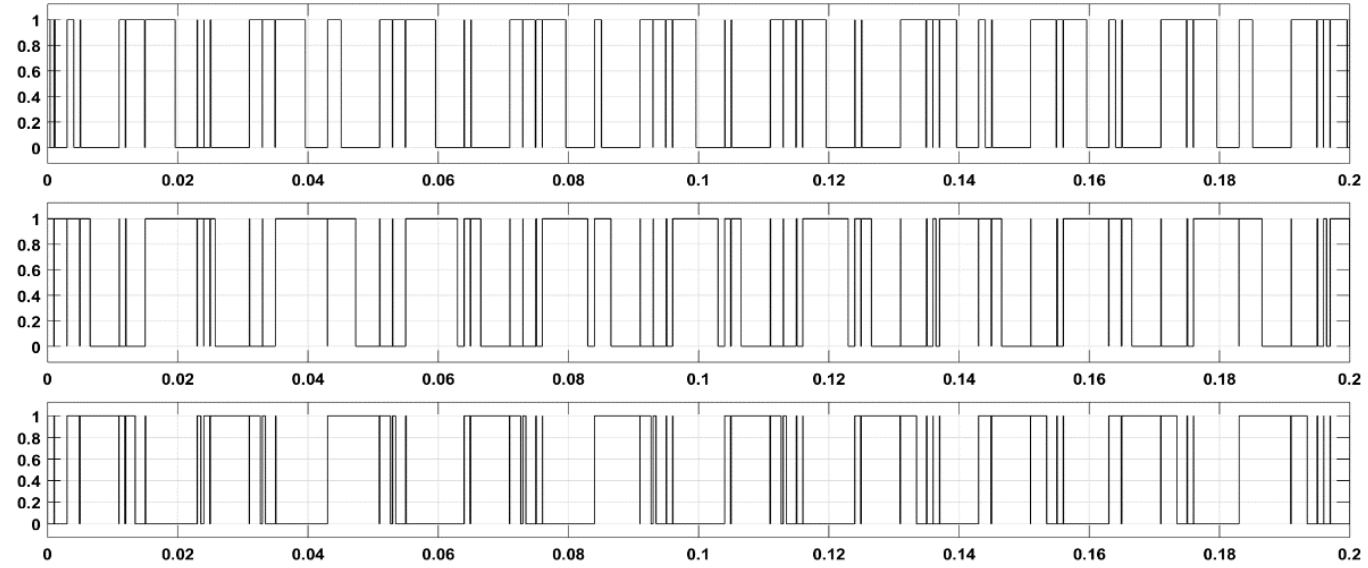

(c)

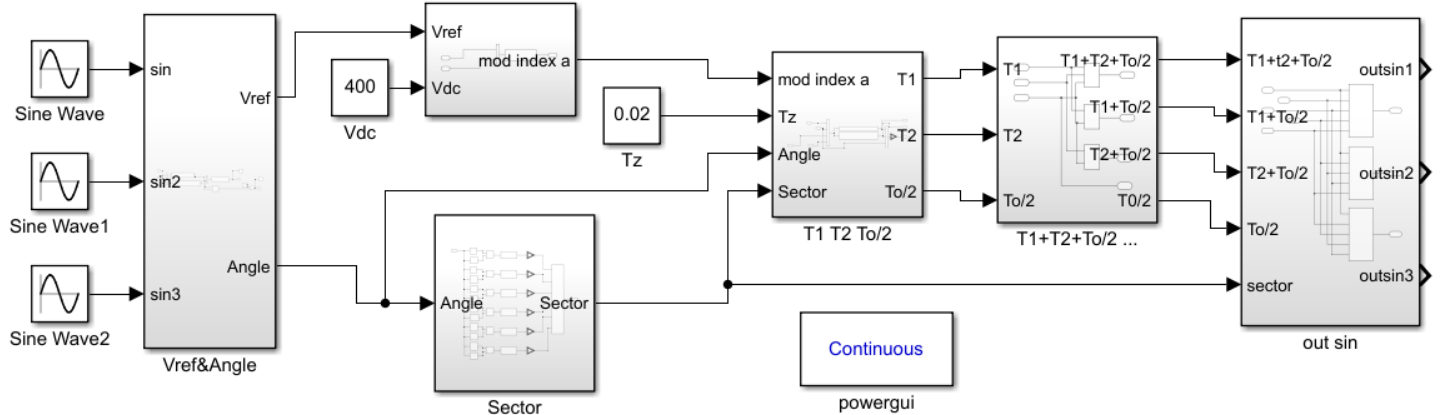

(d)

Figure 6. (a) Identifying the sector, (b) Controlled signals, (c) IGBT'S signals, and (d) Simulink blocks 


\subsection{Determination of the control signals}

The voltage source inverter is best tested when loaded with induction motor because of its dynamic characteristics [17-20]. A three-phase inverter with six IGBT transistors is controlled by the pulses shown in Figure 6 (c). These pulses are PWM signals results when comparing the three phase-controlled signals in Figure 6 (b) with repeating signal (carrier) with frequency $=1 \mathrm{kHz}$ or more to ensure the elimination of more harmonics. It is worth noting that the amplitude of the carrier must be equal to the amplitude of the controlled signals $=0.02$ in this work. The Simulink block diagram with the three phase output voltages are shown in Figures 7 (a) and (b) respectively.

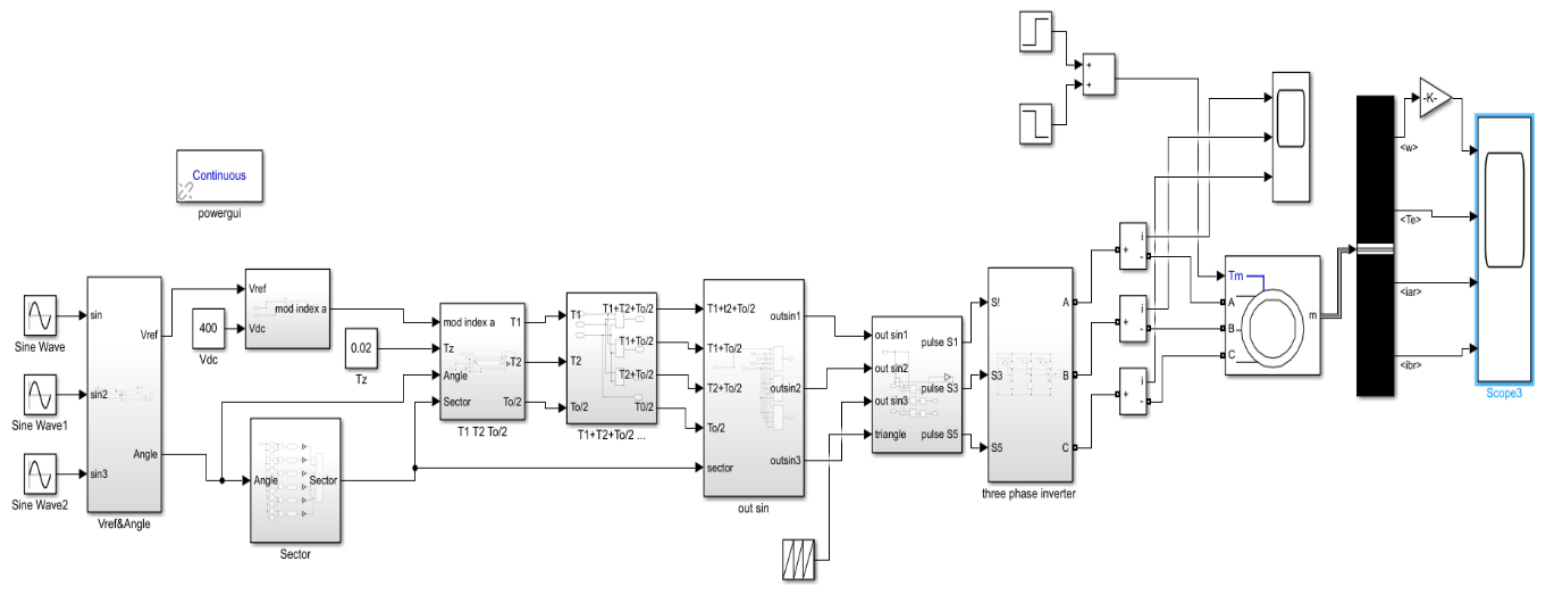

(a)
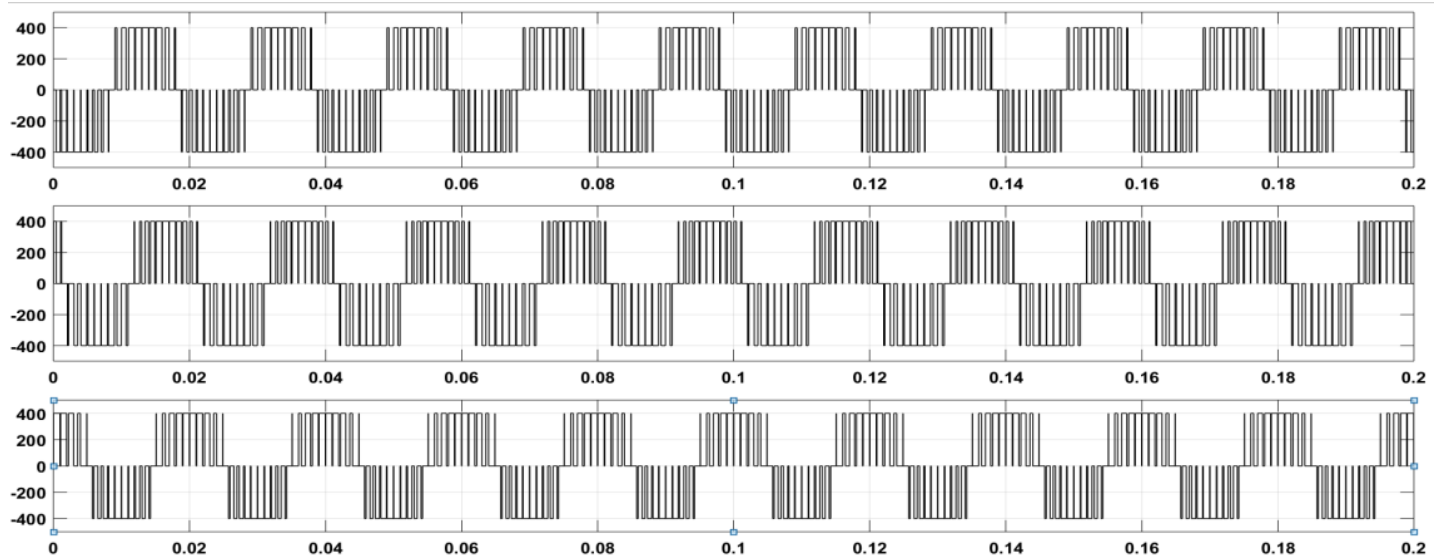

(b)

Figure 7. Complete SVPWM with induction motor load; (a) Simulink model and (b) Three-phase inverter output voltages

The load is asynchronous machine squirrel cage type and has the parameters $5.4 \mathrm{HP}(4 \mathrm{KW}), 400 \mathrm{~V}$, $50 \mathrm{~Hz}, 1430 \mathrm{RPM}$ and a slip $=1430 / 1500=0.9534$. The load is subjected to a change of Torque equal to $20 \mathrm{Nm}$ at step time $=0.5 \mathrm{sec}$, then this external torque is removed at step time $=1 \mathrm{sec}$. Figures 8 (a), (b), and (c) show speed, electrical torque and the three phase currents. The effect of external torque is decreasing the speed, increasing the electrical torque and increasing the three phase currents.

The technique of SVPWM results in lower total harmonic distortion and better utilization of the DC supply compared with traditional sinusoidal pulse width modulation SPWM as seen in Figures 9 (a) and (b) and tabulated in Table 4. Beside the application of SVPWM on the traditional three phase inverter, SVPWM find efficient application in the area of z-source inverter which widen the application of SVPWM on modern electrical systems [21], [22]. The technique of SVPWM can also be implemented without using zero vectors [23]. For high power applications and reduced harmonics elimination multilevel inverters can be implemented with SVPWM [24], [25]. For the purpose of long-time operation and reliability the SVPWM Simulink model is subjected to multiple change in load torque at the instants of 2 and 4 seconds of time, the system responds correctly as expected and shown in Figure 10.

Detailed Simulink implementation for induction motor control based on space vector ... (Taha A. Hussein) 


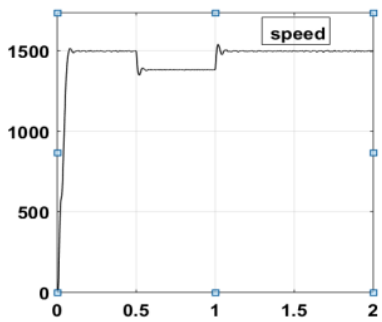

(a)

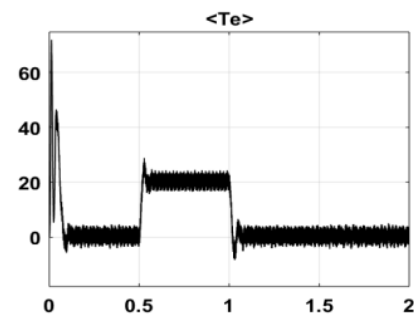

(b)
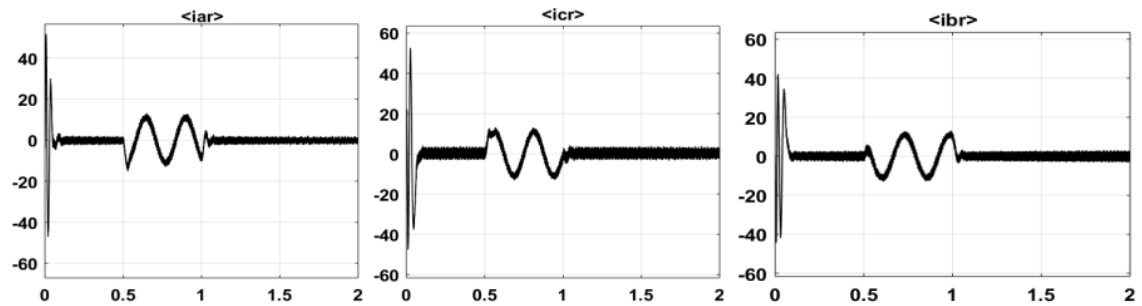

(c)

Figure 8. Effect of external torque on induction motor; (a) motor speed, (b) electrical torque, and (c) three-phase load current

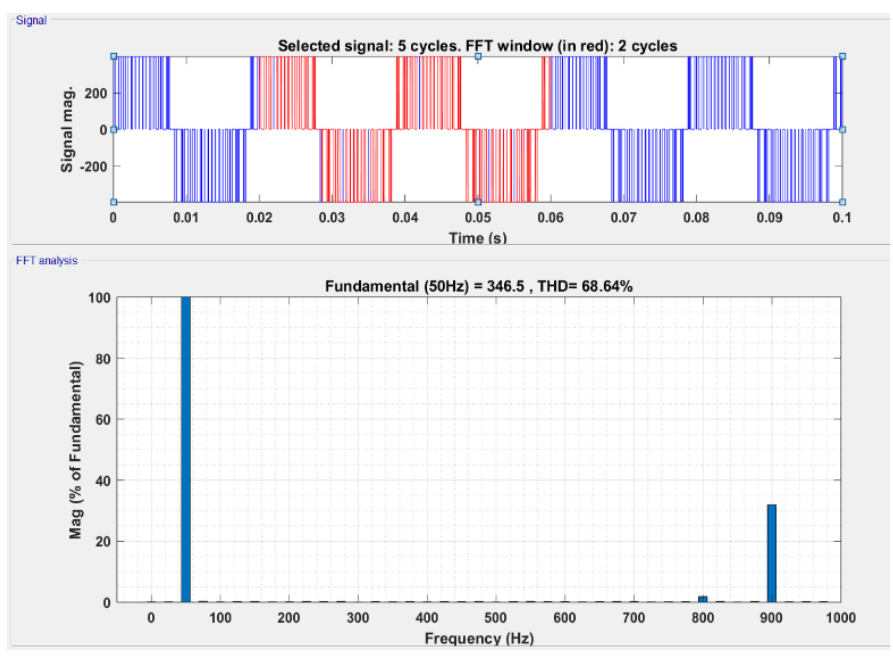

(a)

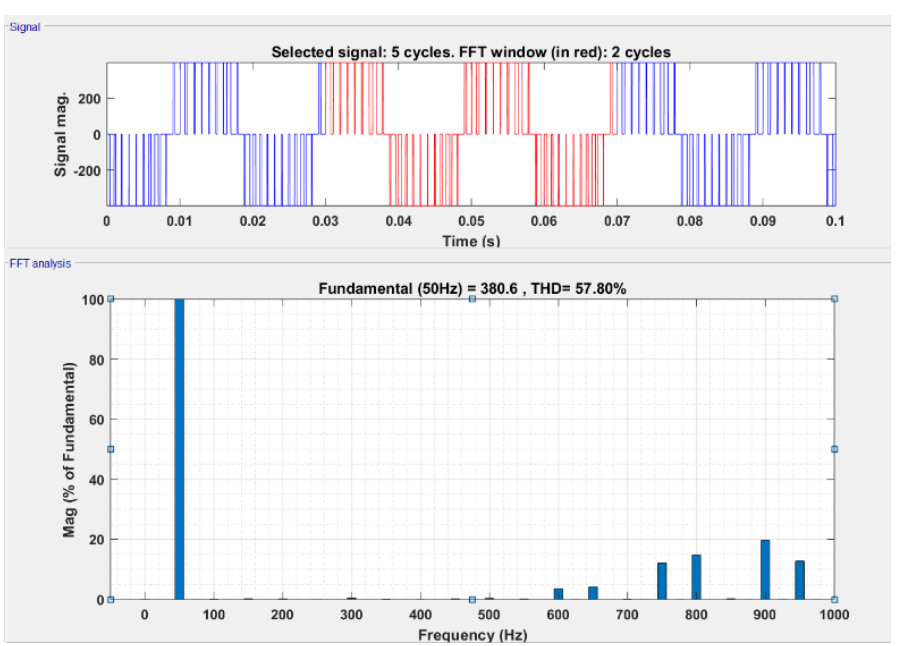

(b)

Figure 9. THD and fundamental components values; (a) SPWM and (b) SVPWM 
Table 4. THD and fundamental components values for SPWM and SVPWM

\begin{tabular}{cccc}
\hline & THD & \multicolumn{2}{c}{ FUNDAMENTAL $(50 \mathrm{~Hz})$} \\
\hline SPWM & 68.64 & & 346.5 \\
SVPWM & 57.80 & 380.6 & \\
\hline
\end{tabular}

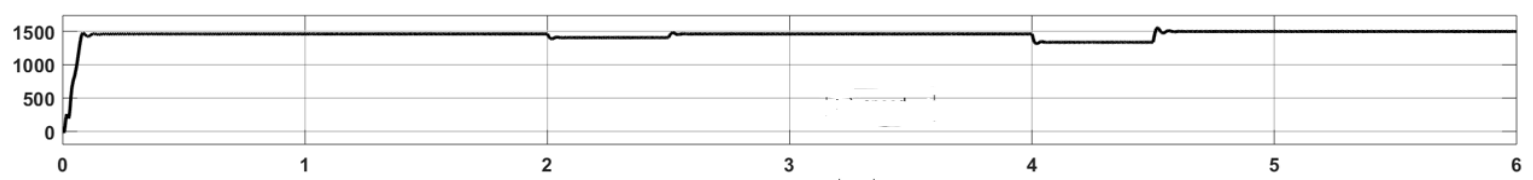

(a)

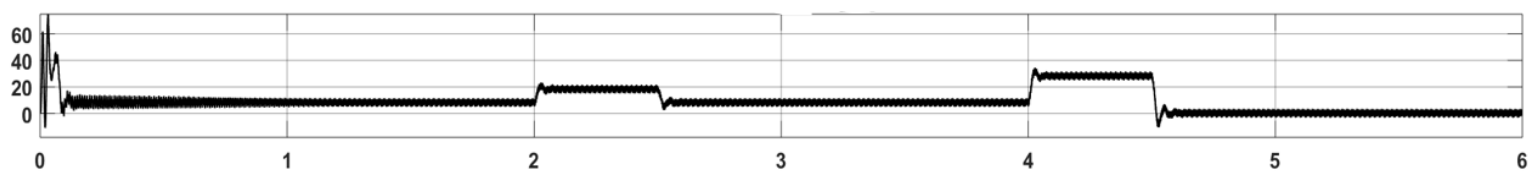

(b)

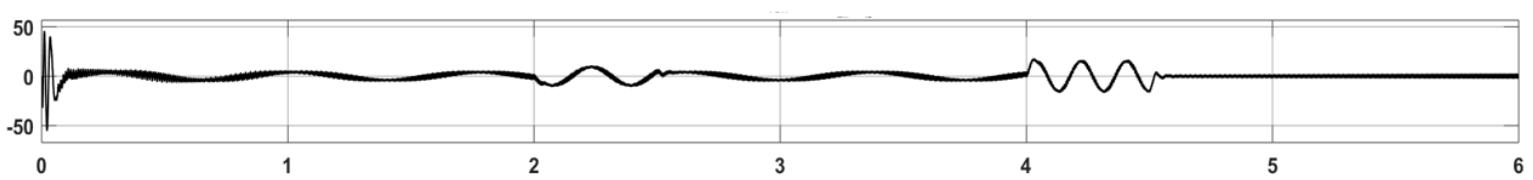

(c)

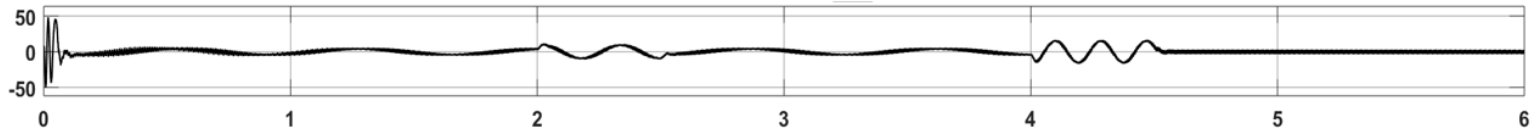

(d)

Figure 10. SVPWM Simulink model subjected to multiple load torque; (a) motor speed,

(b) electrical torque, (c)-(d) phase currents

\section{CONCLUSION}

A detailed SVPWM is introduced and implemented in Simulink Matlab. All necessary equations for the derivation of the concept of SVPWM are given. The outputs of the individual blocks are analyzed. The output pulses of the final block are employed to control the output voltages of three phase inverter. The inverter is loaded with induction motor which in turn is subjected to external torque at chosen instant of time then the external torque is removed after that. The currents and torques of the load respond smoothly to the changes in the external torque. A comparison study of THD and DC utilization shows that SVPWM acts much better than the traditional SPWM for the same DC input voltage and modulation index. The SVPWM shows no complication in the circuitry and finds a wide range of applications in low cost motor drives and in the dc to ac converters especially in solar cell energy generation and many more.

\section{APPENDIX}

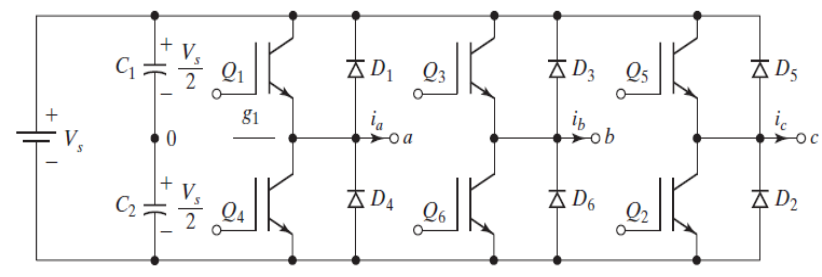

(a)

Figure 3. Modulation index and hexagon: (a) three phase inverter circuit hexagon 


\section{q axis}

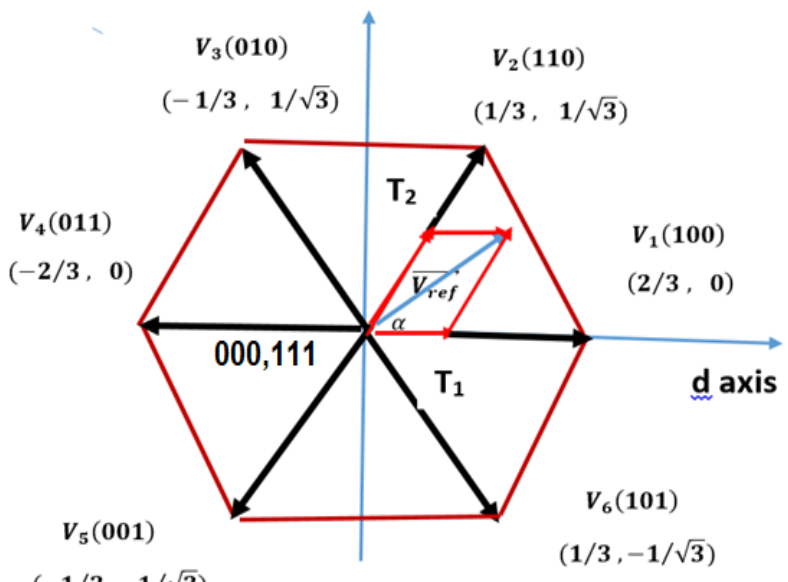

(b)

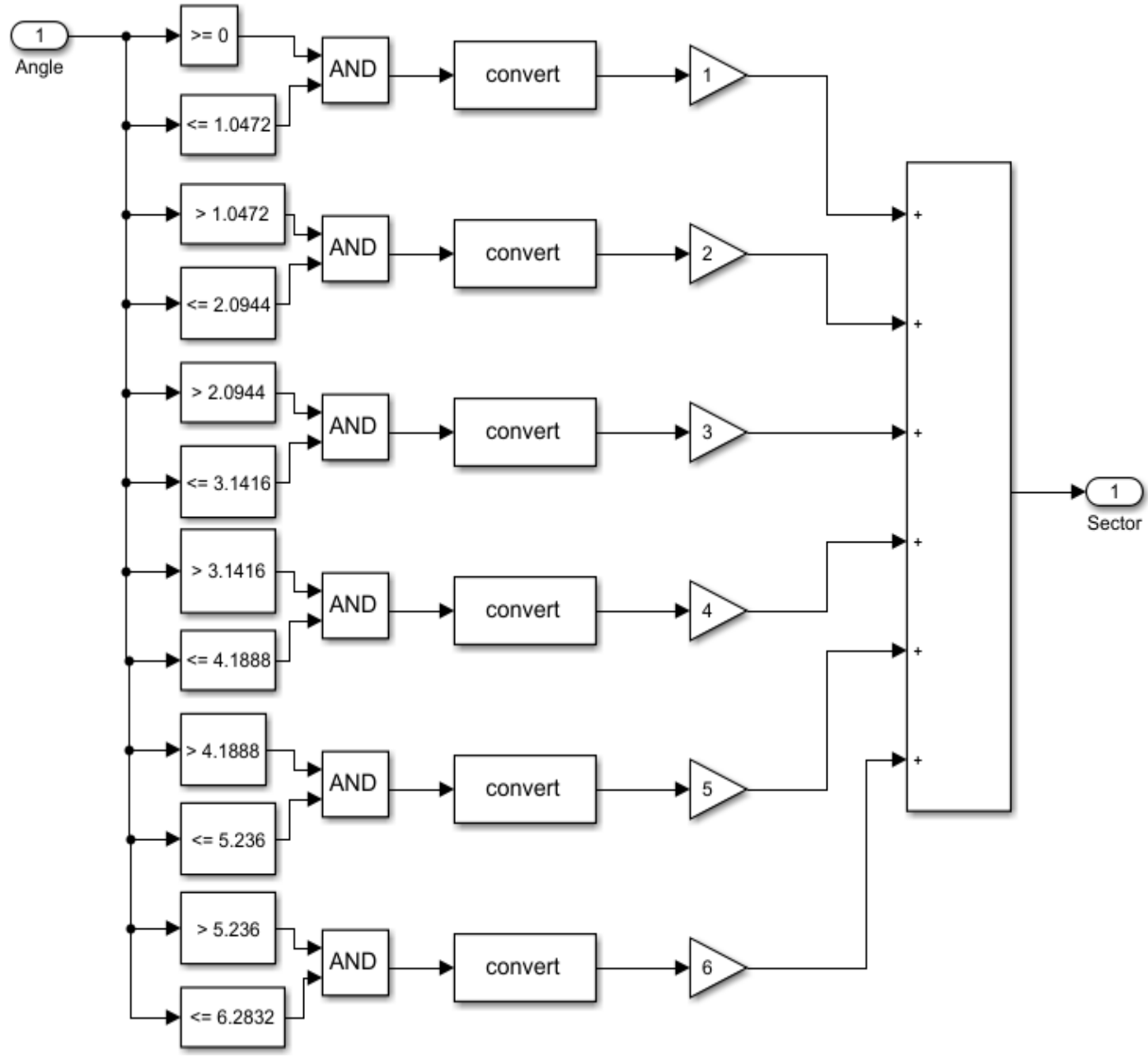

(c)

Figure 3. Modulation index and hexagon: (b) sector determination, (c) sim. block for sector and $\mathrm{m}$ index (continue) 


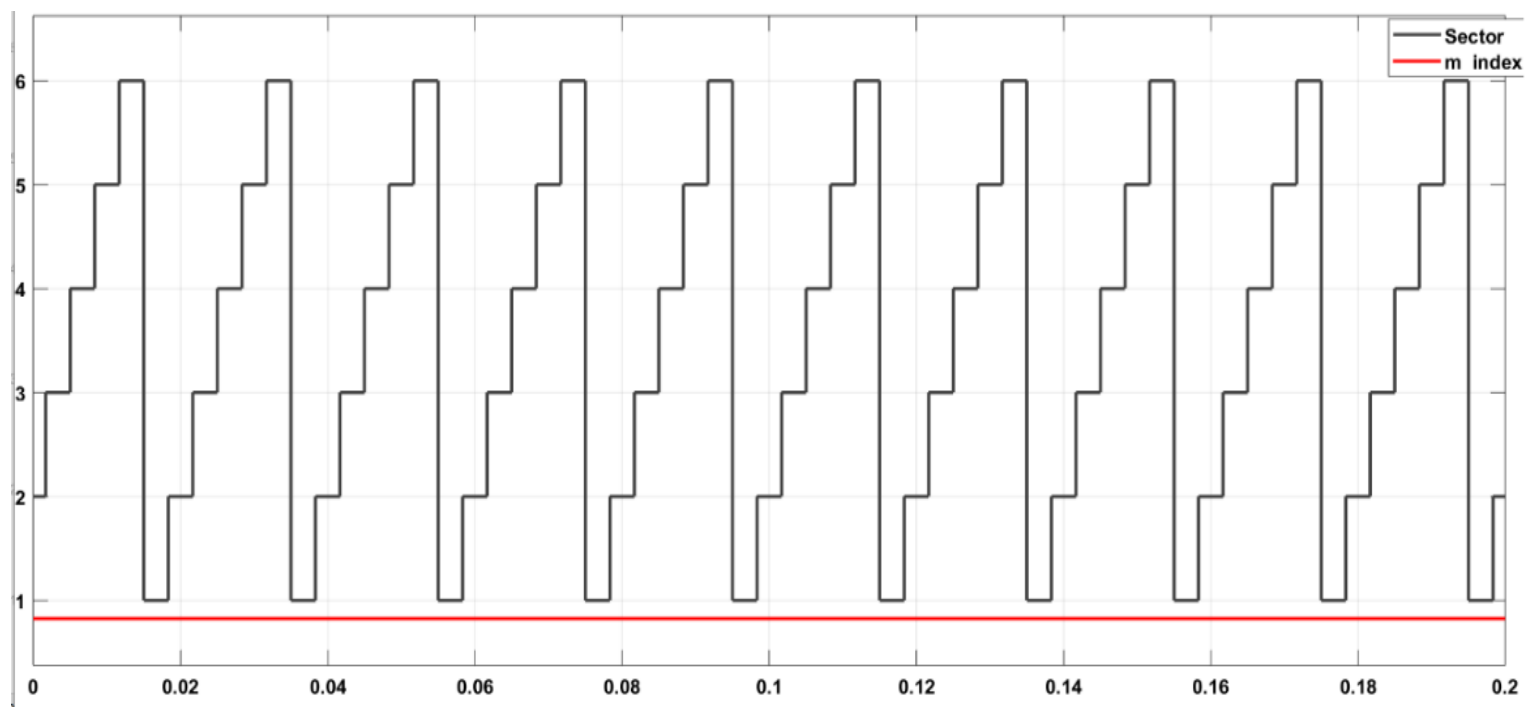

(d)

Figure 3. Modulation index and hexagon: (d) sectors 1-6 (continue)

\section{REFERENCES}

[1] Y. Lee, J. Lee, and J. Lee, "A Simple Novel Method to Reduce Common Mode Voltage in Space Vector Pulse Width Modulation Driving Three-Phase Inverter," International Conference on Electronics, Information and Communications (ICEIC), 2018, doi: 10.23919/ELINFOCOM.2018.8330649.

[2] R. H. Mohammad, "Power electronics, devices, circuits and applications," 4th Edition, Pearson Education, England, 2014.

[3] M. Hasan, S. Mekhilef, and M. Ahmed, "Three-phase hybrid multilevel inverter with less power electronic components using space vector modulation," IET Power Electronics, vol. 7, no. 5, pp. 1256-1265, 2013, doi: 10.1049/iet-pel.2013.0237.

[4] R. Rajendran and N. Devarajan, "Analysis and FPGA Realization of a Pulse Width Modulator based on Voltage Space Vectors," International Journal of Computer Applications, vol. 2, no. 6, pp. 46-51, Jun. 2010, doi: 10.5120/754-997.

[5] M. E. Vijay Kumar, M. G. D. Khadsane, and M. M. Singh, "Study and implementation of space vector close loop control for induction motor," International Journal of Engineering and Technical Research (IJETR), vol. 3, no. 3, Mar. 2015.

[6] A. R. Yilmaz, and B. Erkmen, "FPGA-Based Space Vector PWM and Closed LOOP Controllers Design for the Z Source Inverter," IEEE Access, vol. 7, pp. 130865-130873, Sep. 2019, doi: 10.1109/ACCESS 2019.2940670.

[7] K. A. Chinmaya and G. K. Singh, "Experimental analysis of various space vector pulse width modulation (SVPWM) techniques for dual three-phase induction motor drive" International Transactions on Electrical Energy Systems, vol. 29, no. 1, 2019.

[8] U. V. Patil, H. M. Suryawanshi, and M. M. Renege, "Torque Ripple Minimization in Direct Torque Control Induction Motor Drive Using Space Vector Controlled Diode-clamped Multi-level Inverter," Electric Power Components and Systems, vol. 40, no. 7, pp. 792-806, 2012, doi: 10.1080/15325008.2012.658601.

[9] D. Ronanki and S. S. Williamson, "A Simplified Space Vector Pulse Width Modulation Implementation in Modular Multilevel Converters for Electric Ship Propulsion Systems," IEEE Transactions on Transportation Electrification, vol. 5, no. 1, 2018, doi: 10.1109/TTE.2018.2884610.

[10] X. Xing, C. Zhang A. Chen, J. He, W. Wang, and C. Du, "Space vector-modulated method for boosting and neutral voltage balancing in Z-source three-level T-type inverter," IEEE Trans. Ind. Appl., vol. 52, no. 2, pp. 1621-1631, 2016, doi: 10.1109/TIA.2015.2490142.

[11] E. Hendawi, F. Khater and A. Shaltout, "Analysis, Simulation and Implementation of Space Vector pulse Width Modulation Inverter," International Conference on applications of electrical engineering, 2016.

[12] H. Sathishkumar and S.S.Parthasarathy, "Space Vector Pulse Width Modulation for DC-AC converter", Second International Conference on Science Technology Engineering and Management (ICONSTEM), 2016, pp. 310-314, doi: 10.1109/ICONSTEM.2016.7560968.

[13] S. M. Suhel and R. Maurya, "Modified SVPWM Techniques for Six-Phase Asymmetrical Induction Motor Drives," International Conference on Energy, Systems and Information Processing (ICESIP), 2019, pp. 1-6, doi: 10.1109/ICESIP46348.2019.8938392.

[14] Y. P. Siwakoti, F. Z. Peng, F. Blaabjerg, P. C. Loh, G. E. Town, and S. Yang, "Impedance-source networks for electric power conversion partII: Review of control and modulation techniques," IEEE Trans. Power Electronics, vol. 30, no. 4, pp. 1887-1906, Apr. 2015, doi: 10.1109/TPEL.2014.2329859. 
[15] O. Girgin and V. Erginer, "A novel space vector modulation based control strategy for Z-source inverter," Informacije MIDEM, vol. 48, no. 3, pp. 145-154, 2018.

[16] A. Sharma, A. Singh, and P. Yadav, "Analysis of 3 level SVPWM based open loop and closed loop V/F control of induction motor," International Journal of Engineering Research and Technology (IJERT), vol. 4, no. 4, Apr. 2015, doi: 10.17577/IJERTV4IS041392.

[17] M. Alizadeh, M. Masoumi, and E. Ebrahim, "Closed loop speed control of induction motor using constant V/F applying SPWM and SVM based inverter," International Journal of Engineering and Advanced Technology, vol. 6, no. 5, pp. 234-241, Jun. 2017.

[18] M. S. Aspalli, R. Asha and P. V. Hunagund, "Three Phase Induction Motor Drive Using IGBTs and constant V/F Method," International Journal of Advanced Research in Electrical, Electronics and Instrumentation Engineering, vol. 1, no. 5, pp. 463-469, Nov. 2012.

[19] Y. Zhao, T. Adamson, J. C. Balda and Y. Zhang, "A Frequency-Modulated Space Vector Pulse-Width Modulation for Ripple Current Control of Permanent-Magnet Motor Drives," IEEE Energy Conversion Congress and Exposition (ECCE), 2018, doi: 10.1109/ECCE.2018.8557551.

[20] M. A. Islam, M. B. Hossen, B. Banik and B. C. Ghosh, "Field Oriented Space Vector Pulse Width Modulation Control of Permanent Magnet Brushless DC Motor," IEEE Region 10 Humanitarian Technology Conference (R10HTC), 2017, doi: 10.1109/R10-HTC.2017.8288966.

[21] P. Elanggovan, C. Kumar, and V. Suresh, "Space Vector Modulation based Speed Control of Induction Motor Fed by Z-Source Inverter using PI controller," The International Journal of Engineering and Science (IJES), vol. 2, no. 2, pp. 130-137, 2013.

[22] J. Zhang and R. J. Wai, "Novel Space-Vector Pulse-Width-Modulation Mechanism for Three-Level Neutral-PointClamped Z-Source Inverter", International Conference on Intelligent Green Building and Smart Grid (IGBSG), 2019, pp. 5-9, doi: 10.1109/IGBSG.2019.8886210.

[23] V. Ramesh, P. Anjappa, K. R. Swathi, R. L. Reddy, B. Sambasivarao, "Space Vector Pulse Width Modulation (SVPWM) Using Two Leg Inverter for Split-Phase Induction Motor," International Journal of Scientific \& Engineering Research, vol. 5, no. 5, pp. 660-664, 2014.

[24] S. Chatterjee, "A Multilevel Inverter Based on SVPWM Technique for Photovoltaic Application," International Journal of Power Electronics and Drive System (IJPEDS), vol. 3, no. 1, pp. 62-73, Mar. 2013, doi: 10.11591/ijpeds.v2i4.403.

[25] K. Biju and R. Ramchand, "A New Space Vector Pulse Width Modulation Technique for Single-Phase SevenLevel Inverter with Reduced Number of Switches" The Institution of Electronics and Telecommunication Engineers (IETE), pp. 1-4, Sep. 2019, doi: 10.1080/03772063.2019.1664339. 